\title{
S-Adenosylmethionine: a control switch that regulates liver function
}

\author{
JOSÉ M. MATO, ${ }^{1}$ FERNANDO J. CORRALES, SHELly C. LU,* AND MATÍAS A. AVILA \\ Division of Hepatology and Gene Therapy, School of Medicine, University of Navarra, 31008 \\ Pamplona, Spain; and *Division of Gastrointestinal and Liver Diseases, USC Liver Disease Research \\ Center USC-UCLA Research Center for Alcoholic Liver and Pancreatic Diseases, Keck School of \\ Medicine USC, Los Angeles, California 90033, USA
}

ABSTRACT Genome sequence analysis reveals that all organisms synthesize S-adenosylmethionine (AdoMet) and that a large fraction of all genes is AdoMetdependent methyltransferases. AdoMet-dependent methylation has been shown to be central to many biological processes. Up to $85 \%$ of all methylation reactions and as much as $48 \%$ of methionine metabolism occur in the liver, which indicates the crucial importance of this organ in the regulation of blood methionine. Of the two mammalian genes (MAT1A, $M A T 2 A)$ that encode methionine adenosyltransferase (MAT, the enzyme that makes AdoMet), MAT1A is specifically expressed in adult liver. It now appears that growth factors, cytokines, and hormones regulate liver MAT mRNA levels and enzyme activity and that AdoMet should not be viewed only as an intermediate metabolite in methionine catabolism, but also as an intracellular control switch that regulates essential hepatic functions such as regeneration, differentiation, and the sensitivity of this organ to injury. The aim of this review is to integrate these recent findings linking AdoMet with liver growth, differentiation, and injury into a comprehensive model. With the availability of AdoMet as a nutritional supplement and evidence of its beneficial role in various liver diseases, this review offers insight into its mechanism of action.-Mato, J. M., Corrales, F. J., Lu, S. C., Avila, M. A. S-Adenosylmethionine: a control switch that regulates liver function. FASEB J. 16, 15-26 (2002)

Key Words: knockout mouse $\cdot$ gene expression $\cdot$ liver injury - hepatocyte proliferation

The IDENTIFication By Cantoni in 1951 of S-adenosylmethionine (AdoMet, also abbreviated SAM) was based on the earlier demonstration by du Vigneaud of the transfer of the methyl group of methionine to creatine (1). In 1958, Tabor's group demonstrated that after decarboxylation, AdoMet could donate the propylamino moiety attached to the sulfonium ion to putrescine to form spermidine and methylthioadenosine and to spermidine in order to form spermine and a second molecule of methylthioadenosine (2). Du Vigneaud and others demonstrated in the late 1930s that methionine is a metabolic precursor of homocys- teine and, in the late $1950 \mathrm{~s}$, the methylation of homocysteine to form methionine, an integrated view combining the transmethylation and transsulfuration pathways was finally provided by Laster's group in 1964 (Fig. 1) (3). This seminal work of du Vigneaud, Cantoni, and others provided a perspective of methionine metabolism where AdoMet could be viewed as the main biological methyl donor. Since then, AdoMet-dependent methylation has been shown to be central to many biological processes from metal detoxification through biosynthesis to gene regulation via DNA methylation. Moreover, analysis of genome sequences from archaea, eubacteria, fungi, plants, and animals reveals that all organisms synthesize AdoMet and that a surprisingly large fraction of all genes are AdoMet-dependent methyltransferases.

The crucial importance of the liver in the regulation of blood methionine concentration was first established by Kinsell et al. in 1947 (4), who showed a marked impairment of methionine metabolism in patients with liver cirrhosis. Later work, mainly by the laboratories of Finkelstein and Mudd, demonstrated that under normal conditions, both in humans and rats, $<85 \%$ of all methylation reactions and $\sim 50 \%$ of methionine metabolism occur in the liver $(5,6)$. These authors estimated that the half-life of AdoMet in the liver is $\sim 5 \mathrm{~min}$. In normal liver, the majority of AdoMet is used in methylation reactions, since the AdoMet decarboxylation pathway accounts for less than $10 \%$ of the available AdoMet. In humans, the fraction of available homocysteine converted to cystathionine during each cycle is $53 \%$ and this percent drops to $\sim 20 \%$ when the dietary content of methyl groups is restricted. A central role of AdoMet in the regulation of hepatic methionine metabolism was first proposed by Finkelstein based on his findings that AdoMet activated cystathionine $\beta$-synthase (CBS) and inactivated betaine-homocysteine methyltransferase (7-9), and on the earlier observation of Kutzbach and Stokstad that AdoMet inhibited methylenetetrahydrofolate reductase $(10,11)$. Today, when the discovery of AdoMet reaches its 50 anniversary, this

\footnotetext{
${ }^{1}$ Correspondence: Division of Hepatology and Gene Therapy, School of Medicine, University of Navarra, C/Irunlarrea 1. 31008 Pamplona, Spain. E-mail: jmmato@unav.es
} 
Figure 1. Hepatic methionine metabolism. Methionine (Met) is converted into homocysteine (Hcy) via S-adenosylmethionine (AdoMet) and S-adenosylhomocysteine (AdoHcy). The conversion of Met into AdoMet is catalyzed by the enzyme methionine adenosyltransferase (MAT). After decarboxylation, AdoMet can donate the remaining propylamino moiety attached to its sulfonium ion to putrescine to form spermidine and methylthioadenosine (MTA) and to spermidine to form spermine and a second molecule of MTA. AdoMet donates its methyl group in a large variety of reactions catalyzed by dozens of methyltransferase (MTs), the most abundant in the liver being glycine-N-methyltransferase (GNMT). The AdoHcy thus generated is hydrolyzed to form Hcy and adenosine through a reversible reaction catalyzed by the enzyme AdoHcy hydrolase. The methylation of Hcy to form methionine is catalyzed by two enzymes: methionine synthase (MS) and betaine methyltransferase (BHMT). Hcy, in the presence of serine, forms cystathionine in a reaction catalyzed by the enzyme

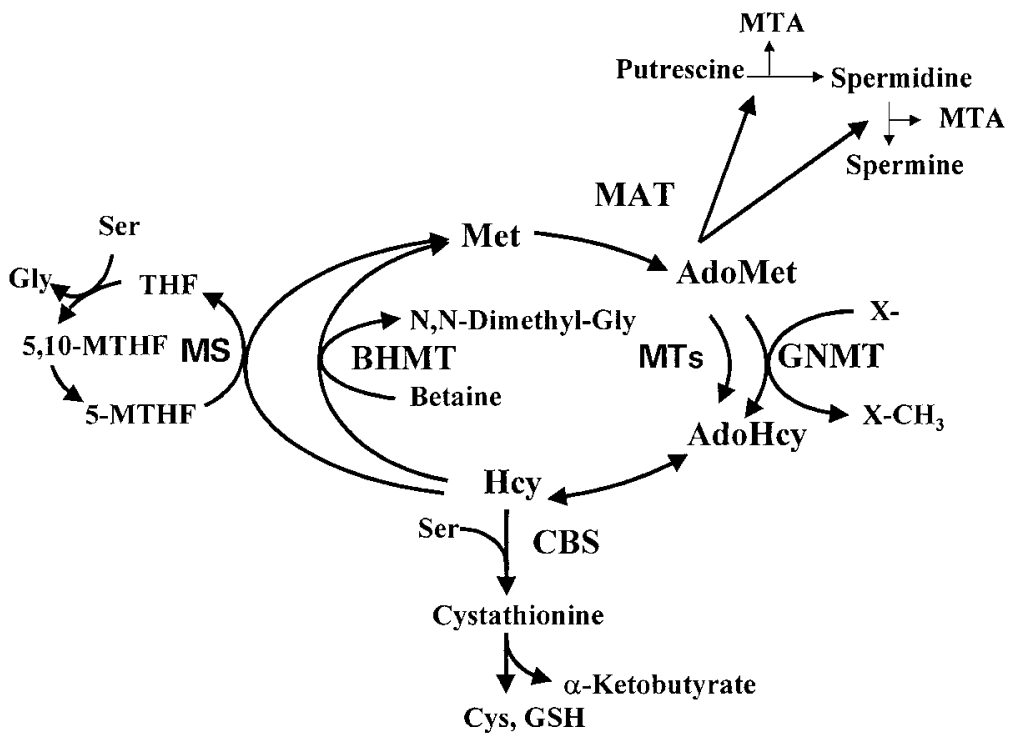
cystathionine $\beta$-synthetase (CBS). Cystathionine is then hydrolyzed to form cysteine, a precursor of the synthesis of glutathione (GSH). THF, tetrahydrofolate; 5,10-MTHF, methylenetetrahydrofolate; 5-MTHF, methyltetrahydrofolate; Ser, serine; Gly, glycine; X, methyl acceptor molecule; $\mathrm{X}-\mathrm{CH}_{3}$, methylated molecule.

molecule is enjoying increased attention and promises to contribute significantly to our understanding of liver function. It now appears that growth factors, cytokines, and hormones regulate hepatic AdoMet synthesis and that AdoMet should not be viewed only as the principal biological methyl donor and a regulator of methionine metabolism, but also as an intracellular signal that controls essential hepatic functions such as hepatocyte growth and differentiation as well as sensitivity to liver injury.

\section{BIOSYNTHESIS OF S-ADENOSYLMETHIONINE}

AdoMet is synthesized from L-methionine and ATP in a two-step reaction where the complete tripolyphosphate (PPPi) moiety is cleaved from ATP as AdoMet is being formed. This unusual reaction is catalyzed by the enzyme methionine adenosyltransferase (MAT, EC 2.5.6.1.; also abbreviated SAM synthetase) (12). The biosynthesis of AdoMet has been studied by the groups of Mudd (13) and Markham (14) using MAT purified from Escherichia coli and mammals, respectively. The cloning and sequencing of the structural genes or cDNAS encoding for a large variety of MATs, including Mycoplasma genitalium, E. coli, Saccharomyces cerevisiae, Arabidopsis thaliana, mouse, rat, and human liver, and mouse, rat, and human kidney, have revealed that MAT is an exceptionally well-conserved enzyme through evolution (15). MAT from E. coli and humans share 59\% sequence identity (16).

MAT from E. coli has been crystallized and the structure solved with a resolution of $2.8 \AA(17)$. The active enzyme exists as a tetramer of a single subunit of 383 amino acids. Each subunit consists of three structural domains related to each other by a pseudo threefold symmetry. Pairs of subunits form dimers, and each dimer is a tight complex, with a wide interface area between subunits that accommodates two active sites. The active site of the enzyme is made by both subunits. The crystal structure of the tetrameric form of MAT (MAT I) from rat liver has been solved with a resolution of $2.7 \AA$ and the geometry of the binding site of methionine identified (18). Each MAT I subunit consists of 396 amino acids and, as expected, the tetramer structure is essentially the same as that of the $E$. coli enzyme with all of the polar active site residues conserved.

Replacement of arginine 264 by histidine $(\mathrm{R} 265 \mathrm{H})$ of MAT I results in a monomeric MAT with undetectable AdoMet synthetic activity (19). The tripolyphosphatase activity of the $\mathrm{R} 265 \mathrm{H}$ mutant was similar to that found in the wild-type MAT. These data suggest that the active site of MAT has two coordinated subsites: a synthetic site, configured by amino acid residues from both subunits (17), that is responsible for the binding of methionine and ATP and performs the AdoMet synthetic reaction; and a hydrolytic site, configured by amino acid residues from one single subunit, which accounts for the binding of PPPi and performs the PPPi hydrolytic reaction.

In the crystal structure of $E$. coli MAT crystallized at $26^{\circ} \mathrm{C}$, residues 102 to 107 , which are located over the active site, are not visible in the electron density maps and have been suggested to form a 'flexible loop' (17). When the crystallization temperature was decreased $\left(4^{\circ} \mathrm{C}\right)$, the amino acid residues forming the loop were in a fixed conformation sealing the active site and preventing the binding of substrates (20). It has been proposed that when a substrate/product binds in the active site, the loop becomes flexible and acts as a 'mobile flap' in the catalytic reaction (20). In the crystal structure of rat liver MAT I, the region comprised by residues 118 to 128 (located over the active site and 
corresponding to the flexible loop in E. coli) is disordered. However, in contrast to the results in E. coli, the conformation of the flexible loop in MAT I was not temperature dependent, suggesting that the mobility of this loop might be a consequence of its direct involvement in catalysis (18). Whereas the exact function of this loop remains unclear, the finding that S-nitrosylation of cysteine 121 completely inactivates MAT I (21) clearly indicates that the flexible loop plays an important role in enzyme activity. Flexible loops have been identified in many protein structures and, in several cases, have been located over the active sites and found to play important roles in enzyme activity. An alignment of 11 MAT sequences in the region of the flexible loop indicates that this region is relatively poorly conserved compared with other parts of the sequence and that the aligned sequences vary in length by two to three residues in this region (20). It has been suggested that the differences in kinetic properties of different MATs may be due in part to differences in the composition of the flexible loop (20).

\section{MAMMALIAN MATS}

Three distinct forms of MAT (MAT I, MAT II, and MAT III) have been identified in mammalian tissues that are the products of two different genes (MAT1A and MAT2A) (13). Kinetic and regulatory properties of the different MAT isoforms in mammalian tissues are summarized in Table 1. The gene MAT2A encodes a 396 amino acid catalytic subunit $\left(\alpha_{2}\right)$ expressed in all mammalian tissues that have been examined including erythrocytes, lymphocytes, brain, kidney and fetal liver, and to a lesser extent in adult liver $(12,15,22,23)$. The structural and kinetic properties of MAT II have been studied by the group of Kotb. MAT II consists of $\alpha_{2}$ and $\beta$ subunits (22). The exact way in which the $\alpha_{2}$ and $\beta$ subunits interact is not yet known. The $\beta$ subunit is a noncatalytic 334 amino acid protein that has no sequence homology with the $\alpha_{2}$ subunit, but has a similarity to enzymes that catalyze the reduction of dTDP-linked sugars (24). Although this reaction has been best studied in bacteria (25), a BLAST search reveals the occurrence of a cDNA from mammalian cells encoding a protein with high similarity to the enzymes that catalyze the reduction of dTDP-linked sugars (26). Whether the $\beta$ subunit has dTDP reductase activity is not yet known. The fact that the expression of the $\alpha_{2}$ subunit in $E$. coli yields an active enzyme indicates that the $\beta$ subunit is not necessary for MAT II activity (27). The function of the $\beta$ subunit is to regulate MAT II activity by lowering its $K_{m}$ for L-methionine and by increasing the sensitivity of the enzyme to feedback inhibition by AdoMet (27). Therefore, regulation of the expression of the $\beta$ subunit may be a mechanism to regulate the intracellular content of AdoMet. This has been shown in $\mathrm{T}$ cells where superantigen stimulation leads to a marked reduction in the expression of the $\beta$ subunit and a fivefold increase in the cellular AdoMet content (28).

The gene MAT1A encodes a 395 amino acid catalytic subunit $\left(\alpha_{1}\right)$ that organizes into dimers, MAT III, and tetramers, MAT I $(12,15)$. The $\alpha_{1}$ and $\alpha_{2}$ subunits share an amino acid sequence identity of $84 \%$ (12). MAT1A is expressed only in adult liver (23), predominantly in the parenchymal cells, although liver endothelial and Kupffer cells have been recently reported to express this gene (29). In developing rat liver, MAT1A expression increases progressively from day 20 of gestation, increases 10-fold immediately after birth, and reaches a peak at 10 days of age, decreasing slightly by adulthood (23). Conversely, MAT2A expression decreases toward birth, increases threefold in the newborn, and decreases further in the postnatal life, reaching a minimum in the adult (23). Consequently, under normal conditions the contribution of MAT II to the hepatic metabolism of methionine is probably negligible due to the small amount of this enzyme expressed in normal liver compared to MAT I and MAT III. It is obvious that the developmental pattern of MAT1A and $M A T 2 A$ are closely related to those of albumin and $\alpha$-fetoprotein, respectively, suggesting that MAT1A is a marker for hepatocyte differentiation (23).

For many years, it has been intriguing why there are two different MAT isoforms in the liver. The majority of methionine is metabolized by this organ and therefore the existence of two different MAT isoforms might be an adaptation to cope with the special metabolic requirements of the liver. In contrast to other mammalian enzymes, methionine has recently been shown to switch MAT III, the predominant liver form, to a higher specific activity conformation, a phenomenon known as hysteretic behavior (30). This has been demonstrated both in vitro with the purified enzyme and in vivo in isolated rat hepatocytes exposed to various physiologi-

TABLE 1. Summary of properties of MAT isoforms in mammalian tissues ${ }^{a}$

\begin{tabular}{|c|c|c|c|c|c|c|c|c|c|}
\hline $\begin{array}{l}\text { MAT } \\
\text { isoform }\end{array}$ & Gene & $\begin{array}{l}\text { Catalytic } \\
\text { subunit }\end{array}$ & $\begin{array}{l}\text { Regulatory } \\
\text { subunit }\end{array}$ & $\begin{array}{c}\text { Subunit } \\
\text { arrangement }\end{array}$ & $\begin{array}{c}\text { Tissue } \\
\text { localization }\end{array}$ & $\begin{array}{c}K_{\mathrm{m}}(\mathrm{Met}) \\
\mu \mathrm{M}\end{array}$ & $\begin{array}{c}K_{\mathrm{m}}(\mathrm{ATP}) \\
\mathrm{mM}\end{array}$ & $\begin{array}{l}\text { Regulation by } \\
\text { ROS and NO }\end{array}$ & $\begin{array}{c}\text { Inhibition by } \\
\text { AdoMet }\end{array}$ \\
\hline MAT I & MAT1A & $\alpha 1$ & No & $(\alpha 1)_{4}$ & Adult liver & $20 ; 600$ & 0.2 & + & No \\
\hline MAT III & MAT1A & $\alpha 1$ & No & $(\alpha 1)_{2}$ & $\begin{array}{l}\text { Adult liver } \\
\text { Extrahepatic } \\
\text { tissues, fetal }\end{array}$ & 120 & 1 & + & No \\
\hline MAT II & $M A T 2 A$ & $\alpha 2$ & $\beta$ & $(\alpha 2)_{\mathrm{x}} \beta_{\mathrm{y}}$ & liver, HCC. & 80 & 0.03 & No & + \\
\hline
\end{tabular}

${ }^{a}$ See text for a detailed description of the regulatory and kinetic properties of the different MAT isoforms in mammalian tissues. 
cal concentrations of methionine (30). The kinetic behavior of MAT I has also been studied by several laboratories, and different $K_{m}$ values for ATP and methionine have been reported (12). Highly purified rat liver MAT I was found to have a sigmoidal kinetics for methionine that could be divided into two components: one with a $K_{m}$ of $\sim 600 \mu \mathrm{M}$ and the second with a $K_{m}$ of $\sim 20 \mu \mathrm{M}(31)$. The $K_{m}$ for ATP was $\sim 200$ $\mu \mathrm{M}(31)$.

It seems that the availability of methionine is probably the determining factor that regulates MAT III activity. The concentration of methionine in rat hepatocytes is between 50 and $80 \mu \mathrm{M}$ (6). Under these conditions, MAT III will be predominantly in the low specific activity conformation and the enzyme responsible for AdoMet synthesis will be MAT I. However, after an increase in methionine concentration, i.e., after a protein-rich meal, conversion to the high activity MAT III form would occur and methionine excess will be rapidly eliminated. Such a mechanism would be very sensitive to changes in methionine concentration. The liver also contains glycine N-methyltransferase (GNMT), a liver-specific enzyme that accounts for $\sim 1 \%$ of the cytosolic protein in this organ, shows positive cooperativity for AdoMet, and whose main function seems to be to remove excess AdoMet synthesized during a methionine load (32). In this way, when large quantities of AdoMet are synthesized by the liver, the excess of this molecule is not used to hypermethylate DNA or proteins or for the synthesis of polyamines, which may be harmful to the liver, but is converted rapidly into S-adenosylhomocysteine by GNMT (Fig. 1). Human subjects with GNMT deficiency have an enormous increase in plasma AdoMet and methionine levels (33). Whereas the increase in plasma AdoMet can easily be explained by the reduction in GNMT activity, the relationship between GNMT deficiency and hypermethioninemia is less clear.

\section{POST-TRANSLATIONAL REGULATION OF MAT ACTIVITY}

The energy required to catabolize methionine is high. For each molecule of AdoMet synthesized, the three high-energy phosphodiester bonds of ATP are hydrolyzed. This may be one reason why MAT1A expression is limited to the liver, an organ with a high capacity to synthesize ATP. Conditions that impair the hepatic capacity to maintain normal ATP levels, as during septic shock or episodes of hypoxia, induce liver MAT inactivation $(34,35)$. This may be a compensatory mechanism to spare ATP and prevent hepatocytes from becoming vulnerable to ATP depletion when energy needs increase acutely. The results showing that expression of MAT1A in nonhepatic cells, such as CHO cells, led to a marked reduction of ATP content and higher sensitivity to cell injury induced by oxidative stress (36) support this concept.
Nitric oxide (NO) and reactive oxygen substances (ROS) have been shown to switch MAT I and MAT III to an inactive conformation through S-nitrosylation (formation of a $-\mathrm{SNO}$ group) and oxidation (formation of a $-\mathrm{SOH}$ group) of a single cysteine residue in position 121 (C121), respectively. The $\alpha_{1}$ subunit from which MAT I and MAT III are made contains 10 cysteine residues. It has been shown that only replacement of cysteine 121 by serine (C121S) yields an active enzyme that is resistant to $\mathrm{NO}$ and ROS inactivation $(34,37)$. Cysteine 121 is located over the active site of the enzyme in the flexible loop described in section 1 of this review, suggesting that the covalent modification of this thiol group switches MAT I/III to an inactive conformation (21). Protein S-nitrosylation involves an acid base-catalyzed nitrosothiol $\mathrm{SNO} / \mathrm{SH}$ exchange reaction where the target cysteine is surrounded by basic and acidic amino acids that reduce the $\mathrm{p} K_{a}$ of its thiol group and make it more nucleophilic (38). Accordingly, MAT S-nitrosylation has been shown to be regulated by the basic (Arg 357, Arg 363) and acidic (Asp 355) amino acids surrounding the target thiol; replacement of any of these three residues by serine markedly reduces the capacity of NO to S-nitrosylate and inactivate liver MAT (21). In MAT II, Arg 357, Arg 363, and Asp 355 are conserved but the equivalent position to C121 in MAT I/III is occupied by a residue of glycine (G120). MAT II is not inactivated by NO, but replacement of $\mathrm{G} 120$ by cysteine $\left(\mathrm{G} 12^{\circ} \mathrm{C}\right)$ yields an active enzyme that, in the presence of NO donors, is Snitrosylated and inactivated (39). An alignment of a large variety of MATs cloned from bacteria, yeast, plants, Drosophila, mouse, rat, and human liver, and mouse, rat, and human kidney has revealed that the presence of a cysteine residue in position 121 is characteristic of the liver enzymes and that all other MATs have a different amino acid in this position, most often a residue of glycine.

Inactivation of MAT I and MAT III by NO or ROS is reversed by physiological (millimolar) concentrations of glutathione $(\mathrm{GSH})(34,37,40)$. In isolated rat hepatocytes, incubation with NO donors or inhibition of GSH synthesis induces the S-nitrosylation and inactivation of MAT and a reduction in AdoMet content (41). Removal of the NO donor from the incubation media or restoration of the cellular GSH levels leads to the denitrosylation and reactivation of liver MAT and to the rapid recovery of AdoMet content (41). Intraperitoneal (i.p.) injection of bacterial lipopolysaccharide (LPS) to rats results in S-nitrosylation and inactivation of hepatic MAT (40). Similarly, inhibition in rats of GSH synthesis by i.p. injection of buthionine sulfoximine leads to the S-nitrosylation and inactivation of hepatic MAT (41).

Liver MAT I/III activity seems to be regulated in a minute-to-minute basis by NO and ROS (which maintain the enzyme in an inactive conformation) and by GSH (which reactivates the enzyme). This may be the mechanism by which a variety of conditions that induce oxidative stress (septic shock, ethanol, hepatitis B- and 
hepatitic C-induced liver cirrhosis, $\mathrm{CCl}_{4}$ ) or increase NO synthesis (hypoxia, liver regeneration, cytokines) inactivate hepatic MAT I/III $(15,34,35,42-44)$. Moreover, these results suggest that liver MAT I/III inactivation may be a key signal to respond to injury.

\section{REGULATION OF MAT1A AND MAT2A EXPRESSION}

MAT1A, MAT2A, and MAT2B promoters have been cloned and sequenced (45-49). The murine and rat MAT1A promoters share limited similarities to the human promoter. The rat and human MAT1A promoters contain several consensus binding sites for $\mathrm{C} / \mathrm{EBP}$ (CAAT enhancer binding protein), NF-1 (nuclear factor 1), and HNF (hepatocyte-enriched nuclear factor), transcriptional factors important in liver-specific gene expression (47-49) (Fig. 2). Two regions spanning nucleotides -1251 to -958 and -197 to +65 were found to be crucial for promoter efficiency in the rat promoter (47). Eight protein binding sites have been characterized in both regions by DNase I footprinting analysis, and two of these regions were found to be essential for the regulation of promoter activity. One region contains a NF1 site, suggesting that NF1, which usually acts as a positive transcription factor, plays a key role in directing MAT1A expression. The second region appears to interact with a member of the HNF-3 family when nuclear extracts from rat liver and H35 hepatoma cells were used, but an additional binding activity to an HNF-1-like protein was obtained with the hepatoma cell extracts (47). It has been suggested that this differential binding may contribute to the negative regulation of MAT1A in human hepatocellular carcinoma (HCC; 47). The MAT1A promoter contains several GRE (glucocorticoid response element) consensus binding sites (47). Consistently, glucocorticoid treatment has been shown to increase rat and human MAT1A expression and promoter activity in a dose- and time-dependent manner $(49,50)$.

Functional analysis by transient transfection has shown that the rat MAT1A promoter is active not only in hepatocytes and liver-type cells such as the human hepatoma cell line HepG2, but also in a nonhepatic cell such as CHO cells (47). These findings suggest that the liver-restricted expression of the endogenous gene is not mediated by the action of tissue-specific factors. It was then found that MAT1A promoter is hypermethylated at two CpG sites in extrahepatic tissues and fetal liver but unmethylated in adult liver, where the gene is actively transcribed $(51,52)$. It has been demonstrated that elevated levels of histone acetylation are critical to maintain a decondensed and active state of the chromatin and the underlying pattern of $\mathrm{CpG}$ methylation modulates histone acetylation (53, 54). Accordingly, the degree of acetylation of histones (H4) associated with MAT1A promoter in the liver is $\sim 15$-fold higher than in the kidney $(51,52)$. In rat and human-derived hepatoma cell lines and HCC, MAT1A is expressed at reduced or undetectable levels whereas MAT2A expression is markedly induced $(55,56)$. It has been found that MAT1A is hypermethylated in HepG2 cells and that treatment of these cells with the demethylating agent 5-aza-2'-deoxycytidine or the histone deacetylase inhibitor trichostatin A results in the induction of MAT1A expression (51). Taken together, these observations indicate that mechanisms involving DNA methylation and histone deacetylation may be the main factors responsible for liver-restricted expression of MAT1A as well as its silencing in neoplastic transformation.

Independent of the etiology (alcohol, hepatitis B, hepatitis C, etc.), MAT1A is expressed at reduced and, in some cases, undetectable levels in human liver cirrhosis whereas the expression of MAT2A remains low (56). It has been shown that MAT1A promoter is hypermethylated in the liver of cirrhotic patients (56), suggesting that this and the increased production of ROS and NO (see section 3 of this review) may be responsible for the impaired hepatic MAT activity (42, $55)$, increased serum levels of methionine $(56,57)$, and abnormal clearance of this amino acid $(4,42,57)$ in human liver cirrhosis. Understanding why MAT1A be-

\section{MAT1A promoter}

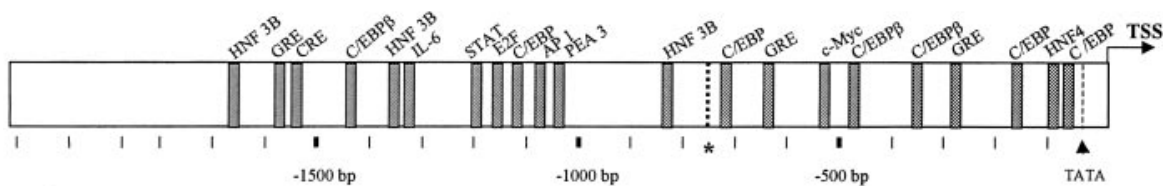

$M A T 2 A$ promoter

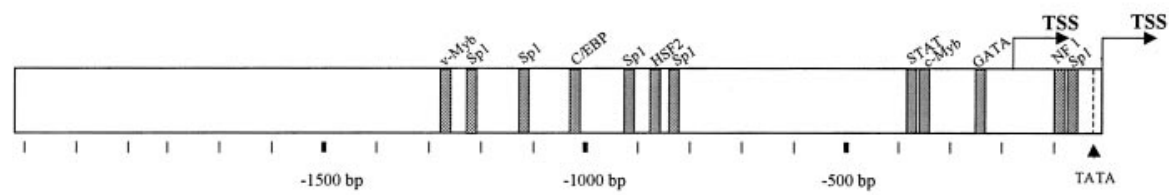

Figure 2. Schematic representation of putative transcription factor binding sites in human MAT1A and MAT2A promoters. HNF-3B (hepatocyte-enriched nuclear factor 3B), GRE (glucocorticoid response element), CRE (cyclic AMP response element), C/EBP (CAAT enhancer binding protein), IL-6 (interleukin-6 response element), STAT (signal transducer and activator of transcription), AP-1 (activator protein 1), PEA3 (polyomavirus enhancer A binding protein 3), HSF2 (heat shock factor 2), TSS (transcription start site). The protein binding sites characterized in detail are described in the text. Asterisk in MAT1A promoter indicates the location of the CpG dinucleotide (position -737) hypermethylated in cirrhotic human liver. 
comes hypermethylated may have applications in the treatment of this disease.

When the methylation pattern of MAT2A promoter was analyzed, no differences were observed between the liver and other tissues where the gene is actively transcribed, such as kidney and spleen (58). Moreover, this analysis showed the same degree of methylation in all three tissues. However, differences in the degree of methylation have been observed between normal liver and in human liver cancer; the human MAT2A promoter is hypomethylated in HCC but hypermethylated in normal liver (59). The reason for these differences is not clear, and the exact role of promoter methylation in MAT2A expression remains to be established. Histones associated with MAT2A promoter are hyperacetylated in kidney and hypoacetylated in liver (60), suggesting that the low activity of MAT2A in liver results from the inaccessibility of transcription factors to binding sites within the condensed chromatin.

In the human MAT2A promoter, two major transcriptional start sites have been identified by primer extension assay: one located within 10 nucleotides downstream of the TATA box and another one 158 nucleotides upstream from the TATA box (48) (Fig. 2). The MAT2A promoter is highly rich in GC $(75 \%)$ in the first 300 base pairs and contains several Sp-1 binding sites, a C/EBP, a HSF2 (heat shock transcription factor 2), a STAT (signal transducer and activator of transcription), a c-Myb, v-Myb, and GATA consensus binding sites $(48,61)$ (Fig. 2). Two protein binding sites have been characterized by DNase I footprinting analysis (61). These protected sites $(-354$ to -312 and -73 to -28) contain consensus binding sites for c-Myb and Sp1. Mutation of any of these two sites markedly reduces MAT2A promoter activity (61), suggesting that c-Myb and Sp1 may contribute to the up-regulation of $M A T 2 A$ transcription in HCC. In support of this view, it has been observed that the mRNA levels of c-Myb and Sp1 are induced in HCC and that overexpression of these two factors increases MAT2A promoter expression (61). Treatment of Jurkat cells with interleukin 2 (IL-2) increases MAT2A mRNA levels and stimulates MAT2A promoter activity (62). This effect of IL-2 on MAT2A expression seems to be mediated by $\mathrm{c}-\mathrm{Myb}$ (62). Thus, treatment of Jurkat cells with IL-2 increases c-Myb mRNA content, and the overexpression in these cells of c-Myb increases MAT2A promoter activity. Moreover, mutation of the MAT2A c-Myb site blocked the stimulatory of IL-2 on c-Myb nuclear binding and MAT2A promoter activities in Jurkat cells. Taken together, these observations indicate that mechanisms involving the acetylation of histones associated with the gene and the interaction of its promoter with $\mathrm{c}-\mathrm{Myb}$ and Sp1 may be among the main factors responsible for the increased expression of MAT2A during liver regeneration and neoplastic transformation.

Liver regeneration is a fundamental feature of the response of this organ to injury. Caused by hepatotoxins or partial hepatectomy, liver mass loss initiates a cellular response involving a vast number of growth factors, cytokines, and transcription factors that has positive and negative effects on liver until the restoration of normal hepatic architecture and function (63). In regenerating liver after partial hepatectomy, a switch in MAT gene expression has been observed: MAT2A is induced and MAT1A mRNA levels decrease $(60,64)$. The induction of MAT2A expression is accompanied by a marked increase in the acetylation of the histones (H4) associated with the promoter of this gene (60). $M A T 2 A$ is induced in culture hepatocytes and MAT1A mRNA levels decrease (65), a situation reminiscent of that found in fetal and regenerating liver and in HCC. Addition of hepatocyte growth factor (HGF, a potent mitogen for hepatocytes that plays a key role in liver regeneration) (63) to culture hepatocytes markedly stimulates the acetylation of histones associated with $M A T 2 A$ promoter and expression of the gene (60). The effect of HGF on MAT2A expression is prevented by AdoMet (60) through a mechanism that involves inhibition of growth factor-induced acetylation of histones (H4) associated with the gene promoter (A. Avila, L. Torres, L., and J. M. Mato, unpublished results). On the other hand, the reduction of MAT1A expression in hepatocytes in culture is prevented by AdoMet through a mechanism that remains unclear, but may involve protein methylation (65). In $\mathrm{HuH}-7$ cells differing only in the type of MAT gene that is expressed, MAT2A expression associates with more rapid cell growth whereas the opposite is observed for MAT1A (66). Cells expressing MAT2A had lower AdoMet levels than cells expressing MAT1A and treatment of $\mathrm{HuH}-7$ cells with AdoMet led to reduced cell growth (66). These data suggest AdoMet has a growth modulatory effect. In fact, addition of AdoMet to culture hepatocytes has been found to markedly inhibit the mitogenic activity of HGF (65). Although AdoMet has no effect on the activation of extracellular signal-regulated protein kinase (ERK) (67) by HGF, this molecule strongly inhibits HGFdependent induction of cyclin D1 and D2 expression, indicating that AdoMet suppresses HGF-induced signals between ERK activation and cyclin D1 and D2, resulting in the inhibition of DNA synthesis (E. R. Garcia-Trevijano, J. M. Mato, and M. A. Avila, unpublished results). Downstream of ERK activation, the up-regulation of D-type cyclins collectively control cell cycle progression by activating the cell cycling kinases CDK4 and CDK6, which leads to phosphorylation of the retinoblastoma protein and to acceleration of the $\mathrm{G}_{1}$ phase of the cell division cycle (68). Cyclin D1 is induced in rodents after partial hepatectomy and in regenerating human liver (69); moreover, its overexpression promotes mitogen-independent cell cycle progression in rat hepatocytes (70). Genes encoding Dtype cyclins are themselves proto-oncogenes and, in several types of tissues, can be turned into oncogenes by viruses and overexpression (71). AdoMet therapy has been shown to be effective in preventing the growth of rat HCC $(72,73)$. These findings provide a new and unexpected view of AdoMet as a modulator of cell cycle. 
As expected, MAT1A null (MATO) mice have increased serum methionine levels and reduced hepatic AdoMet content ( $\sim$ fourfold reduction) (74). MATO mice display a phenotype resembling that observed in liver injury or stress with a vast array of growth, dedifferentiation, and acute-phase response genes (such as proliferating cell nuclear antigen, $\alpha$-fetoprotein, and orosomucoid) up-regulated (74). Although histologically normal, 3-month-old MATO mice have hepatic hyperplasia, are more prone to develop liver injury, and at 8 months of age develop nonalcoholic steatohepatitis (NASH) (74). Since hepatic hyperplasia may precede the appearance of liver cancer (75), it will be important to know whether the risk for HCC is increased in MATO mice.

The available data indicate that 1) in hepatocytes AdoMet content regulates the type of MAT gene that is expressed and 2) the type of MAT gene expressed strongly influences the rate of cell growth and DNA synthesis. The main difference between MAT1A and MAT2A is that MAT I/III, the enzymes encoded by MAT1A, can maintain higher intracellular AdoMet concentrations than MAT II, the enzyme encoded by MAT2A (see section 1). Under normal conditions, MAT I/III are the main enzymes present in the liver and the hepatic AdoMet content is maintained at a high level. Consequently, MAT1A expression is high and MAT2A mRNA levels remain very low. Liver mass loss, caused by hepatotoxins or partial hepatectomy, initiates a cellular response involving the generation of NO and $\operatorname{ROS}(63,76)$ (Fig. 3). This leads to the inactivation of MAT I/III and a concomitant reduction of AdoMet content, which in turn produces a reduction of MAT1A expression and a further decrease in MAT I/III activity and AdoMet synthesis. The reduction in AdoMet content releases the inhibition that this molecule exerts on the mitogenic activity of HGF (through its blocking effect on HGF-induced cyclin D1 and D2 expression) as well as on the expression of MAT2A. In response to liver injury, MAT I/III (both expression and activity) is switched off and MAT II expression is switched on; hepatic content of AdoMet changes to a new lower steady-state level that facilitates the progression of the cell division cycle and hepatocyte growth. During restoration of the original liver mass, the inhibitory effect that NO and ROS exert on MAT I/III activity is released, MAT1A expression is induced, AdoMet content increases, and MAT2A expression is again switched off, which may help the liver to recover its normal nonproliferative metabolic phenotype.

\section{MATO MOUSE, A NOVEL MODEL THAT ILLUSTRATES THE IMPORTANCE OF A DEFICIENCY IN MAT I/III AND ADOMET IN THE PATHOGENESIS OF LIVER INJURY}

It is known that when rats and mice are fed a diet deficient in lipotropes (choline, methionine, folate, and vitamin B12) the liver develops steatosis within a

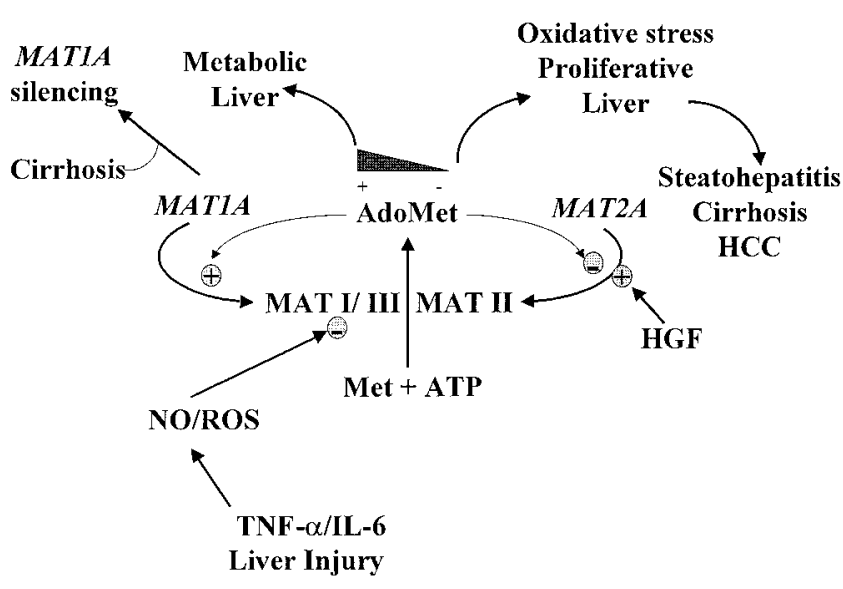

Figure 3. Regulation of liver function by AdoMet. Under normal conditions two main mechanisms operate in the liver that maintain the high cellular concentration of AdoMet: 1) up-regulation by AdoMet of MAT1A expression, with the concomitant increase in MAT I/III activity; and 2) the high capacity of MAT I/III to convert dietary methionine into AdoMet. Since AdoMet down-regulates MAT2A expression and inhibits MAT II activity, the contribution of this enzyme to the net synthesis of hepatic AdoMet under normal conditions is small. Liver injury caused by hepatotoxins or partial hepatectomy initiates a cellular response that involves a vast number of growth factors and cytokines (such as HGF, TNF- $\alpha$, and IL-6) and generation of oxidative stress (NO and ROS). The increased production of NO and ROS leads to the inactivation of MAT I/III and a reduction of hepatic AdoMet content. This reduction in AdoMet content induces an increase in MAT2A expression and MAT II activity (which is not inactivated by NO or ROS). As a result, a new, lower steadystate level of AdoMet is reached. The reduced content of hepatic AdoMet releases the inhibitory effect that this molecule exerts on the proliferative activity of HGF, which facilitates liver regeneration. On restoration of the original liver mass, the inhibitory effect that NO and ROS exert on MAT I/III is released, MAT1A expression is induced, AdoMet content returns to its original value, and MAT2A expression is again down-regulated. However, if the conditions leading to oxidative stress persist (e.g., chronic exposure to alcohol, $\mathrm{HBV}, \mathrm{HCV})$, the hepatic levels of AdoMet are maintained continuously low, which predisposes the liver to injury and to develop steatohepatitis, cirrhosis, and ultimately HCC. In the cirrhotic liver, MAT1A expression is progressively silenced by a mechanism that involves the methylation of the gene promoter and its association with hypoacetylated histones.

few days (77). If the diet continues, the liver develops NASH, fibrosis, and cirrhosis, with some animals developing HCC (78). Numerous nutritional studies have shown that dietary methyl insufficiency causes a decrease in hepatic levels of AdoMet and an increase in AdoHcy content $(79,80)$. Is lipotrope deficiency exerting its pathogenic effect in the liver through a decreased availability of AdoMet? The observation that MATO mice have hepatic hyperplasia, are more prone to develop liver injury (e.g., in response to a choline deficient diet), and spontaneously develop NASH (74) strongly suggests that AdoMet deficiency may be a key component of the mechanism by which lipotrope deficiency causes hepatic lesions. The question then is, How does a decreased availability of AdoMet lead to NASH? 
The similarity of hepatic lesions between NASH and alcoholic steatohepatitis (ASH) suggests the possibility that similar mechanisms may be involved in their pathogenesis. Numerous studies support the view that alcohol contributes to the development of liver disease by generating oxidative stress through its induction of the microsomal enzyme cytochrome P4502E1 (CYP2E1) (81-83). In the alcoholic, CYP2E1 is induced by ethanol as a substrate; in the nonalcoholic, CYP2E1 is induced by ketones and a high-fat diet (84). CYP2E1 catalyzes the formation of ROS and lipid peroxidation derivatives (81-83). CYP2E1 metabolizes ethanol and other endogenous (e.g., fatty acids, ketones) and xenobiotic (e.g., acetaminophen) compounds to reactive metabolites and ROS, which can injure cell membranes and promote hepatocyte death (81-83). Formation of ROS can occur even in the absence of added substrates, as indicated by the finding that the generation of ROS from microsomes of CYP2E1-expressing cells was not altered by addition of substrates and ligands of CYP2E1 (85). The important role of CYP2E1 in ethanol-induced ROS production, GSH depletion, and cell death has been confirmed using cell lines transfected with the microsomal enzyme (86). Moreover, there is a close correlation between induction of CYP2E1 activity and alcoholic liver disease $(81,85)$, and inhibitors of CYP2E1 ameliorate alcoholic liver injury (87). CYP2E1 knockout mice are, however, just as susceptible to alcoholic liver injury as the wild-type animals (88), which questions the essential role of this microsomal enzyme in the development of ASH. Similarly, CYP2E1 knockout mice are not protected from the development of NASH induced by a methionine/cholinedeficient (MCD) diet (89). In CYP2E1 knockout mice that developed NASH, but not in the wild-type mice, CYP4A10 and CYP4A14 are induced, suggesting that members of the CYP4A family may substitute for CYP2E1 as catalysts of hepatic lipid peroxidation (89). Whether CYP4A enzymes are up-regulated in CYP2E1 mice after ethanol-induced liver injury is not known. The finding that hepatic CYP2E1 activity is induced in patients with NASH (90) and in rats and mice where NASH is induced by feeding a MCD diet (84) also suggests a role for this microsomal enzyme in its pathogenesis. However, Zucker rats and ob/ob mice, which develop obesity, diabetes, and hepatic steatosis, do not exhibit CYP2E1 induction but display constitutive up-regulation of CYP4A (91). It appears that induction of microsomal enzymes (mainly CYP2E1 and CYP4A) may be necessary but not sufficient to develop ASH and NASH. Other factors essential for the development of ASH and NASH (e.g., the magnitude of the oxidative stress imposed to the liver or the underlying immune status of the host) remain to be investigated.

In MATO mice, the levels of liver CYP2E1 mRNA and enzyme activity are markedly induced whereas mRNA levels of CYP4A10 and CYP4A14 are decreased (74; M. A. Avila, F. J. Corrales, and J. M., Mato, unpublished results), indicating that a decrease in AdoMet content generates oxidative stress. This conclusion is further supported by the following: 1) the hepatic content of uncoupling protein 2 (UCP2) mRNA, an anion carrier that uncouples the respiratory chain from oxidative phosphorylation and influences generation of ROS and ATP (and hence might enhance the vulnerability of hepatocytes to necrosis) (84), is also induced in MATO mice with respect to wild-type animals (M. A. Avila, F. J. Corrales, and J. M. Mato, unpublished results); 2) the hepatic mRNA levels of several key enzymes of the trans-sulfuration pathway involved in cysteine and GSH synthesis-CBS, $\gamma$-glutamylcysteine synthetase heavy (GCS-HS) and light (GCS-LS) subunits, and GSH synthetase-are increased in MATO mice $(74 ; \mathrm{S}$. C. Lu, unpublished results); and 3) the hepatic content of GSH, a critical factor for preserving normal cellular redox balance and protecting hepatocytes against oxidative stress, is reduced by $\sim 50 \%$ in MATO mice (74). Whereas the induction of CYP2E1 expression and depletion of GSH content generate oxidative stress, the increase in CBS, GCS-HS, GCS-LS, and GSH synthetase is probably an adaptation of the liver to this stress (92, 93). Since AdoMet is a precursor of hepatic GSH, it seems obvious why a deficiency in MAT activity may lead to GSH depletion. The exact mechanism by which a reduction in AdoMet increases the hepatic content of CYP2E1 mRNA is unclear and needs to be investigated. The answer may lie in whether AdoMet, through the action of specific methyltransferases or AdoMet binding proteins, is involved in the down-regulation of CYP2E1. Releasing this inhibition by lowering hepatic AdoMet content may lead to a progressive induction of CYP2E1 expression by endogenous physiological substrates of the microsomal enzyme, making the liver more susceptible to develop injury. This may be part of the mechanism by which a diet deficient in choline or folates induces CYP2E1 in the liver. A deficiency in these lipotropes causes homocysteine accumulation through the inhibition of its conversion to methionine and, consequently, an increase in S-adenosylhomocysteine (AdoHcy) levels (note in Fig. 1 that AdoHcyhydrolase, the enzyme that converts AdoHcy into homocysteine, is the only reversible enzyme of the cycle) $(15,79,80)$. Since AdoHcy is a potent competitive inhibitor of many transmethylation reactions, its accumulation may inhibit a key AdoMet-dependent methylation reaction or AdoMet binding protein involved in the down-regulation of CYP2E1 and release the control that AdoMet exerts on hepatic oxidative stress. Identifying these target proteins will be challenging, since the liver contains dozens of methyltransferases and probably as many AdoMet binding proteins.

Consistent with the concept of oxidative stress caused by a deficiency in AdoMet, MATO mice are more prone to develop liver injury. Thus, feeding a choline deficient diet for only 6 days in 3-month-old MATO mice induced severe macrovesicular steatosis, whereas in wild-type animals it caused little histological change or only mild steatosis (74). Macrovesicular steatosis of both alcohol- and nonalcohol-related etiologies is associated with the development of steatohepatitis, fibrosis, 
and cirrhosis (75). At 8 months of age, MATO mice spontaneously developed NASH (74). MATO mice are more likely than wild-type animals to develop liver injury in response to $\mathrm{CCl}_{4}$. After $\mathrm{CCl}_{4}$ administration the activity of transaminases and the serum concentration of thiobarbituric acid-reactive substances were much higher in MATO mice than in wild-type animals (F. J. Corrales, M. A. Avila, and J. M. Mato, unpublished results). The histological liver injury caused by $\mathrm{CCl}_{4}$ was much more severe in MATO mice than in wild-type animals. To establish the role of CYP2E1 in $\mathrm{CCl}_{4^{-}}$ induced liver injury, MATO mice and wild-type animals were treated with diallylsulfide (DAS), an effective inhibitor of CYP2E1. The addition of DAS prevented $\mathrm{CCl}_{4}$-induced liver injury in both MATO mice and wild-type animals. These findings strongly suggest that AdoMet deficiency may be a key factor in the development of NASH and ASH.

In contrast to these findings in MATO mice, human MAT I/III deficiency has not been associated with hepatic pathology (94). However, the number of individuals identified with mutations in the MAT1A gene is small (11 patients and 3 pedigrees) and, with the exception of a 43-year-old individual, are young (under 14 years) (94). It is then possible that AdoMet deficiency may be necessary but not sufficient to develop liver pathology. Therefore, the possibility that these patients may be at risk for developing liver pathology at a later age cannot be excluded.

A variety of hepatotoxic agents (e.g., $\mathrm{CCl}_{4}$, ethanol, LPS) are known to induce the inactivation of hepatic MAT and AdoMet depletion (15). The complete prevention by DAS of $\mathrm{CCl}_{4}$-induced hepatic MAT inactivation and AdoMet depletion in mice (F. J. Corrales, M. A. Avila, and J. M. Mato, unpublished results) suggests that CYP2E1-derived ROS may play a key role in the inactivation of this enzyme during liver injury (see section 3). Conversely, in MATO mice the addition of $\mathrm{CCl}_{4}$ has no effect on hepatic MAT activity (F. J. Corrales, M. A. Avila, and J. M. Mato, unpublished results). These results agree with the observation made in vitro that MAT I/III but not MAT II is inactivated by ROS and NO (see section 3). This linkage between CYP2E1 oxidative stress and hepatic MAT inactivation may sensitize the liver to oxidative injury and sets up a vicious cycle since, as previously seen, AdoMet depletion causes oxidative stress through the up-regulation of CYP2E1 and GSH depletion, which in turn may cause a further reduction in MAT activity and AdoMet content. Consistent with this model, GSH depletion by buthionine sulfoximine treatment caused hepatic MAT inactivation; the addition of the ethyl ester of GSH (a permeable derivative of GSH) prevented this effect (15).

\section{USE OF AdoMet AS A THERAPEUTIC AGENT FOR LIVER DISEASE}

In cirrhotic patients, the progressive silencing of MAT I/III (expression and activity) caused by this condition may impose the liver to additional oxidative stress (through the induction of CYP2E1 and depletion of GSH) that will contribute to progression and complications of the disease. Preventing AdoMet deficiency may then be a major therapeutic target for the treatment of human liver diseases. As reviewed elsewhere $(15,95)$, a variety of clinical studies indicate that AdoMet treatment, given either orally or parenterally, is beneficial in intrahepatic cholestasis. Thus, in a multicenter double-blind, placebo-controlled clinical trial performed in 220 patients with chronic liver disease, AdoMet treatment significantly improved serum markers and subjective symptoms of cholestasis (95). Similar findings have been obtained in a variety of blind and open studies, and a metanalysis of the results of these studies confirmed the efficacy of the drug (15, 95). AdoMet treatment has been shown to be beneficial in severe cholestasis of pregnancy $(15,95)$. Moreover, in patients with alcoholic liver disease, oral administration of $1.2 \mathrm{~g} /$ day of AdoMet for 6 months resulted in a significant increase in hepatic GSH (15); in animal models of alcoholic liver disease and $\mathrm{CCl}_{4}$ hepatotoxicity, exogenous administration of AdoMet prevented the depletion of AdoMet and GSH levels and significantly ameliorated liver injury, including fibrosis $(15,95)$.

Based on these experimental and clinical results, a study was designed to investigate the effects of AdoMet treatment ( $1.2 \mathrm{~g}$ /day, orally) in 123 patients (106 men and 17 women) in a double-bind, randomized, placebocontrolled multicenter over a 24 month period (96). All patients had alcoholic liver cirrhosis and histological confirmation of the diagnosis was available in $84 \%$ of cases. Seventy-five patients were in Child class A, 40 in class B, and 8 in class C. Efficacy of the treatment was analyzed in terms of mortality from any cause or liver transplantation during a period of $<2$ years. The overall mortality/liver transplantation at the end of the trial decreased from $30 \%$ in the placebo group to $16 \%$ in the AdoMet group, although the difference was not statistically significant $(P=0.077)$. When patients with more advanced cirrhosis (Child $\mathrm{C}$ ) were excluded from the analysis, the overall mortality/liver transplantation was significantly greater in the placebo group than in the AdoMet group ( $29 \%$ vs. $12 \%, P=0.025$ ); differences between the two groups in the 2-year survival curves (defined as the time to death or liver transplantation) were statistically significant $(P=0.046)$. These results indicate that long-term treatment with AdoMet may improve survival or delay liver transplantation in patients with alcoholic liver cirrhosis, especially those with less advanced liver disease. Furthermore, this study has shown that treatment with AdoMet is safe and is free of secondary effects.

How does AdoMet exert its therapeutic effects in the liver? Since MAT activity is markedly decreased in liver diseases, it has been assumed that the consequences of this enzymatic defect can be alleviated by supplementing AdoMet, the product of the reaction. However, due to the presence of a sulfonium ion in its structure, AdoMet bioavailability is poor. Therefore, the amount 
of AdoMet that may enter the liver after its administration is small and its half-life short (around $5 \mathrm{~min}$ ) (5, 6). When $1.2 \mathrm{~g}$ /day of AdoMet is administered orally, probably not more than half reaches the liver after crossing the intestinal barrier, of which (again) only a small fraction will cross the plasma membrane and enter the hepatocytes. Since a normal liver makes and consumes around $5 \mathrm{~g}$ /day of AdoMet, supplementation with $1.2 \mathrm{~g}$ /day orally or $200 \mathrm{mg}$ /day i.v. of AdoMet will not contribute significantly to the daily hepatic requirement of this compound. On the other hand, AdoMet treatment provides the liver with a fast and transient increase in the content of this molecule that will be rapidly consumed in methylation reactions and ultimately used for the synthesis of GSH. This transient increase in hepatic AdoMet content may stimulate MAT1A expression (Fig. 3) and, through its conversion into GSH, reactivate MAT I/III subunits that may have been inactivated by NO or ROS, leading to increased synthesis of AdoMet. In this way, the biological effect of exogenous AdoMet will be amplified, and this may explain its therapeutic activity in liver diseases. This model can also explain why AdoMet treatment had no effect in patients with more advanced cirrhosis (Child C) (96): in these patients, MAT1A has been found to be silenced by methylation of the promoter (56); consequently, AdoMet supplementation will not be able to stimulate its transcription.

This work was supported by grants 99/0038 from Plan Nacional de I+D Ministerio de Educación y Ciencia, 681/ 2000 'Ortiz de Landazuri' from Gobierno de Navarra, Europharma, and Knoll to J.M.M., grant ROI AA-12677 from the National Institute on Alcohol Abuse and Alcoholism to J.M.M., S.C.L., and M.A.A., grant 349/2001, 'Ortiz de Landazuri' from Gobierno de Navarra to M.A.A., National Institutes of Health grants R01 DK51719 and R01 DK45334 to S.C.L., grant P30 DK48522 (USC Liver Disease Research Center), and grant P50 AA11999 (USC-UCLA Research Center for Alcoholic Liver and Pancreatic Diseases).

\section{REFERENCES}

1. Cantoni, G. L. (1975) Biochemical methylations: selected aspects. Annu. Rev. Biochem. 44, 435-441

2. Tabor, C. W., and Tabor, H. (1976) 1,4-Diaminobutane (putrescine), spermidine and spermine. Annu. Rev. Biochem. 45, 285-306

3. Finkelstein, J. D. (2000) Homocysteine: a history in progress. Nutr. Rev 58, 193-204

4. Kinsell, L. W., Harper, H. A., Marton, H. C., Michael, G. D., and Weiss, H. A. (1947) Rate of disappearance from plasma of intravenously administered methionine in patients with liver damage. Science 106, 589-590

5. Mudd, S. H., and Poole, J. R. (1975) Labile methyl balances for normal humans of various dietary regimens. Metabolism 24, $721-735$

6. Finkelstein, J. D. (1990) Methionine metabolism in mammals. J. Nutr. Biochem. 1, 228-236

7. Finkelstein, J. D., Kyle, W. E., and Martin, J. J., and Pick, A. M. (1975) Activation of cystathionine synthase by S-adenosylmethionine and S-adenosylmethionine. Biochem. Biophys. Res. Commun. 66, $81-87$

8. Finkelstein, J. D., and Martin, J. J. (1984) Inactivation of betaine-homocysteine methyltransferase by S-adenosylmethi- onine and S-adenosylhomocysteine. Biochem. Biophys. Res. Commun. 118, 14-19

9. Finkelstein, J. D., and Martin, J. J. (1984) Methionine metabolism in mammals: distribution of homocysteine between competitive pathways. J. Biol. Chem. 259, 9508-9513

10. Kutzbach, C., and Stokstad, E. L. R. (1967) Feedback inhibition of methylene-tetrahydrofolate reductase in rat liver by S-adenosylmethionine. Biochim. Biophys. Acta 139, 217-220

11. Kutzbach, C., and Stokstad, E. L. R. (1971) Mammalian methylene-tetrahydrofolate reductase: partial purification, properties and inhibition by S-adenosylmethionine. Biochim. Biophys. Acta 250, $459-477$

12. Kotb, M., Mudd, H. S., Mato, J. M., Geller, M. A., Kredich, N. M., Chou, J. Y., and Cantoni, G. L. (1997) Consensus nomenclature for the mammalian methionine adenosyltransferase genes and gene products. Trends Genet. 13, 51-52

13. Mudd, S. H. (1962) Activation of methionine for transmethylation. The mechanism of action of the methionine-activating enzyme. J. Biol. Chem. 237, 1372-1375

14. Markham, G. D., Hafner, E. W., Tabor, C. W., and Tabor, H. (1980) S-adenosylmethionine synthetase from Escherichia coli. J. Biol. Chem. 255, 9082-9092

15. Mato, J. M., Alvarez, L., Ortiz, P., and Pajares, M. A. (1997) S-Adenosylmethionine synthesis: molecular mechanisms and clinical implications. Pharmacol. Ther. 73, 265-280

16. Alvarez, L., Asunción, M., Corrales, F. J., Pajares, M. A., and Mato, J. M. (1991) Analysis of the $5^{\prime}$ non-coding region of rat liver S-adenosylmethionine synthetase mRNA and comparison of the $\mathrm{M}_{\mathrm{r}}$ deduced from the cDNA sequence and the purified enzyme. FEBS Lett. 290, 142-146

17. Takusagawa, F., Kamitori, S., Misaki, S., and Markham, G. D. (1996) Crystal structure of S-adenosylmethionine synthetase. J. Biol. Chem. 271, 136-147

18. González, B., Pajares, M. A., Hermoso, J. A., Alvarez, L., Garrido, F., Sufrin, J. R., and Sanz-Aparicio, J. (2000) The crystal structure of tetrameric methionine adenosyltransferase from rat liver reveals the methionine-binding site. J. Mol. Biol. 300, 363-375

19. Pérez-Mato, I., Sánchez del Pino, M. M., Chamberlin, M. E., Mudd, S. H., Mato, J. M., and Corrales, F. J. (2001) Biochemical basis for the dominant inheritance of hypermethioninemia associated with the $\mathrm{R} 264 \mathrm{H}$ mutation of the MAT1A gene. A monomeric methionine adenosyltransferase with tripolyphosphatase activity. J. Biol. Chem. 276, 13803-13809

20. Fu, Z., Hu, Y., Markham, G. D., and Takusagawa, F. (1996) Flexible loop in the structure of S-adenosylmethionine synthetase crystallized in the tetragonal modification. J. Biomol. Struct. Dynam. 13, 727-739

21. Pérez-Mato, I., Castro, C., Ruiz, F. A., Corrales, F. J., and Mato, J. M. (1999) Methionine adenosyltransferase S-nitrosylation is regulated by the basic and acidic amino acids surrounding the target thiol. J. Biol. Chem. 274, 17075-17079

22. Kotb, M., and Geller, A. M. (1993) Methionine adenosyltransferase: structure and function. Pharmacol. Ther. 59, 125-143

23. Gil, B., Casado, M., Pajares, M. A., Bosca, L., Mato, J. M., Martin-Sanz, P., and Alvarez, L. (1996) Differential expression pattern of S-adenosylmethionine synthetase isoenzymes during rat liver development. Hepatology 24, 876-881

24. LeGros, H.L.Jr., Halim, A-B., Geller, A. M., and Kotb, M. (2000) Cloning, expression, and functional characterization of the $\beta$ regulatory subunit of human methionine adenosyltransferase (MAT II). J. Biol. Chem. 275, 2359-2366

25. Yoshida, Y., Nakano, Y., Nezu, T., Yamashita, Y., and Koga, T. (1999) A novel NDP-6-deoxyhexosyl-4-ulose reductase in the pathway for the synthesis of thymidine diphosphate-D-fucose. J. Biol. Chem. 274, 16933-16939

26. Tonetti, M. (1999) Homo sapiens mRNA for dTDP-4-keto-6deoxy-D-gluocse 4-reductase (tgr gene). GenBank accession AJ243721

27. Halim, A-B., Le Gros, L., Geller, A. M., and Kotb, M. (1999) Expression and functional interaction of the catalytic and regulatory subunits of human methionine adenosyltransferase in mammalian cells. J. Biol. Chem. 274, 29720-29725

28. LeGros, H.L.Jr., Geller, A. M., and Kotb, M. (1997) Differential regulation of methionine adenosyltransferase in superantigen and mitogen stimulated human T lymphocytes. J. Biol. Chem. 272, $16040-16047$ 
29. Shimizu-Saito, K., Horikawa, S., Kojima, N., Shiga, J., Senoo, H., and Tsukada, K. (1997) Differential expression of S-adenosylmethionine synthetase isoenzymes in different cell types of rat liver. Hepatology 26, 424-431

30. Sanchez del Pino, M. M., Corrales, F. J., and Mato, J. M. (2000) Hysteretic behavior of methionine adenosyltransferase III. Methionine switches between two conformations of the enzyme with different specific activity. J. Biol. Chem. 275, 23476-23482

31. Pajares, M. A., Duran, C., Corrales, F. J., Pliego, M. M., and Mato, J. M. (1992) Modulation of rat liver S-adenosylmethionine synthetase activity by glutathione. J. Biol. Chem. 267, 1759817605

32. Wagner, C., Pattaneyek, R., Newcomer, M., and Krupenko, N. (1998) Glycine N-methyltransferase: structure and function. In Methionine Metabolism: Molecular Mechanisms and Clinical Implications (Mato, J. M., and Caballero, A. eds) pp. 35-43, CSIC, Madrid

33. Mudd, S. H., Cerone, R., Schiaffino, M. C., Fantasia, A. R., Minniti, G., Caruso, U., Lorini, R., Watkins, D., Matiaszuk, N., Rosenblatt, D. S., Schwahn, B., Rozen, R., LeGros, L., Kotb, M., Capdevila, A., Luka, Z., Finkelstein, J. D., Tangerman, A., Stabler, S. P., Allen, R. H., and Wagner, C. (2001) Glycine N-methyltransferase deficiency: a novel inborn error causing persistent isolated hypermethioninemia. J. Inherit. Metab. Dis. 24 In press

34. Avila, M. A., Mingorance, M.L., Martinez-Chantar, M. L., Casado, M., Martin-Sanz, P., Bosca, L., and Mato, J. M. (1997) Regulation of rat liver S-adenosylmethionine synthetase during septic shock: role of nitric oxide. Hepatology 25, 391-396

35. Avila, M. A., Carretero, M. V., Rodriguez, N., and Mato, J. M. (1998) Regulation by hypoxia of methionine adenosyltransferase activity and gene expression in rat hepatocytes. Gastroenterology 114, 364-371

36. Sanchez-Gongora, E., Pasrtorino, J. G., Alvarez, L., Pajares, M. A., Garcia, C., Vina, J. R., Mato, J. M., and Farber, J. L. (1996) Increased sensitivity to oxidative injury in chinese hamster ovary cells stably transfected with rat liver S-adenosylmethionine synthetase cDNA. Biochem. J. 319, 767-773

37. Sanchez-Gongora, E., Ruiz, F., Mingorance, J., An, W., Corrales, J. M., and Mato, J. M. (1997) Interaction of liver methionine adenosylltransferase with hydroxyl radical. FASEB J. 11, 10131019

38. Stamler, J. S., Toone, E. J., Lipton, S. A., and Sucher, N. J. (1997) (S) NO signals: translocation regulation, and a consensus motif. Neuron 18, 619-696

39. Castro, C., Ruiz, F. A., Perez-Mato, I., Sanchez del Pino, M. M., LeGros, L., Geller, M., Kotb, M., Corrales, F. J., and Mato, J. M. (1999) Creation of a functional S-anitrosylation site in vitro by single point mutation. FEBS Lett. 459, 319-322

40. Ruiz, F., Corrales, F. J., Miqueo, C., and Mato, J.M. (19998). Nitric oxide inactivates rat hepatic methionine adenosyltransferase in vivo by S-nitrosylation. Hepatology 28, 1051-1057

41. Corrales, F. J., Ruiz, F., and Mato, J. M. (1999) In vivo regulation by glutathione of methionine adenosyltransferase S-nistrosylation in rat liver. J. Hepatol. 31, 887-894

42. Martin-Duce, A., Orriz, P., Cabrero, C., and Mato, J. M. (1988) S-Adenosylmethionine synthetase and phospholipid methyltransferase are inhibited in human cirrhosis. Hepatology 8, 65-68

43. Cabrero, C., Martin-Duce, A., Ortiz, P., Alemany, S., and Mato, J. M. (1988) Specific loss of the high molecular weight form of S-adenosylmethionine synthetase in human liver cirrhosis. Hepatology 8, 1530-1534

44. Lu, S. C., Huang, Z. Z., Yang, H. P., Mato, J. M., Avila, M. A., and Tsukamoto, H. (2000) Changes in methionine adenosyltransferase and S-adenosylmethionine homeostasis in alcoholic rat liver Am. J. Physiol. 379, G178-G185

45. Hiroki, T., Horikawa, S., and Tsukada, K. (1997) Structure of the rat methionine adenosyltransferase $2 \mathrm{~A}$ gene and its promoter. Eur. J. Biochem. 250, 653-660

46. LeGros, L., Halim, A. B., Chamberlin, M. E., Geller, A., and Kotb, M. (2001) Regulation of the human MAT2B gene encoding the regulatory beta subunit of methionine adenosyltransferase, MAT II. J. Biol. Chem. 276, 24918-24924

47. Alvarez, L., Sanchez-Gongora, E., Mingorance, J., Pajares, M. A., and Mato, J. M. (1997) Characterization of rat liver-specific methionine adenosyltransferase gene promoter. Role of distal upstream cis-acting elements in the regulation of the transcription activity. J. Biol. Chem. 272, 22785-22883

48. Mao, Z., Liu, S., Cai, J., Huang, Z. Z., and Lu, S. C. (1998) Cloning and functional characterization of the $5^{\prime}$-flanking region of human methionine adenosyltransferase 2A gene. Biochem. Biophys. Res. Commun. 248, 479-484

49. Zeng, Z., Huang, Z-Z., Chen, C., Yang, H., Mao, Z., and Lu, S. C. (1999) Cloning and functional characterization of the $5^{\prime}$-flanking region of human methionine adenosyltransferase 1A gene. Biochem. J. 346, 475-482

50. Gil, B., Pajares, M.A. Mato, J. M., and Alvarez, L. (1997) Glucocorticoid regulation of hepatic S-adenosylmethionine synthetase gene expression. Endocrinology 138, 1251-1258

51. Torres, L., Avila, M. A., Carretero, M. V., Latasa, M. U., Caballeria, J., Lopez-Rodas, G., Boukaba, A., Lu, S. C., Franco, L., and Mato, J. M. (2000) Liver-specific methionine adenosyltransferase MAT1A gene expression is associated with a specific pattern of promoter methylation and histone acetylation: implications for MAT1A silencing during transformation. FASEB J. 14, 95-102

52. Torres, L., Lopez-Rodas, G., Latasa, M. U., Carretero, M. V., Boukaba, Abdelhalim, Rodriguez, J. L., Franco, L., Mato, J. M., and Avila, M. A. (2000) DNA methylation and histone acetylation of rat methionine adenosyltransferase $1 \mathrm{~A}$ and $2 \mathrm{~A}$ genes is tissue-specific. Int. J. Biochem. Cell Biol. 32, 397-404

53. Singal, R., and Ginder, G. D. (1999) DNA methylation. Blood 93, 4059-4070

54. Cheung, P., Allis, C. D., and Sassone-Corsi, P. (2000) Signaling to chromatin through histone modifications. Cell 103, 263-271

55. Cai, J., Sun, W.-M., Hwang, J.-J., Stain, S. C., and Lu, S. C. (1996) Changes in S-adenosylmethionine synthetase in human liver cancer: molecular characterization and significance. Hepatology 24, 1090-1097

56. Avila, M. A., Berasain, C., Torres, L., Martin-Duce, A., Corrales, F. J., Yang, H., Prieto, J., Lu, S. C., Caballeria, J., Rodes, J., and Mato, J. M. (2000) Reduced mRNA abundance of the main enzymes involved in methionine metabolism in human liver cirrhosis and hepatocellular carcinoma. J. Hepatol. 33, 907-914

57. Horowitz, J. H., Rypins, E. B., Henderson, J. M., Heymsfield, S. B., Moffit, S. D., Bain, R., Chawla, R. K., Bleier, J. C., and Rudman, D. (1981) Evidence for impairment of transsulfuration pathway in cirrhosis. Gastroenterology 81, 668-675

58. Avila, M. A., García-Trevijano, E. R., Torres, L., Latasa, M. U., Carretero, M. V., Roman, J. P., Fernandez, E., Boukaba, A., Lopez-Rodas, G., Franco, L., and Mato, J. M. (2000) Methyl groups in the regulation of MAT1A and MAT2A gene expression. In Methionine Metabolism: Molecular Mechanisms and Clinica Implications (Mato, J. M., and Caballero, A., eds) pp. 91-104, Master Line, S.L. Spain

59. Yang, H., Huang, Z. Z., Chen, C., Selby, R. R., and Lu, S. C. (2001) Role of promoter methylation in increased methionine adenosyltransferase 2A expression in human liver cancer. Am. J. Physiol. 280, G184-G190

60. Latasa, M. U., Boukaba, A., García-Trevijano, E. R., Torres, L., Rodriguez, J. L., Caballería, J., Lu, S. C., Lopez-Rodas, G., Franco, L., Mato, J. M., and Avila, M. A. (2001) Hepatocyte growth factor induces MAT2A expression and histone acetylation in rat hepatocytes: role in liver regeneration. FASEB J. (March 5, 2001) 10.1096/fj.00-0556fje

61. Yang, H., Huang, Z.Z. Wang, J., and Lu, S. C. (2001) The role of c-Myb and Spl in the up-regulation of methionine adenosyltransferase $2 \mathrm{~A}$ gene expression in human hepatocellular carcinoma. FASEB J. 15, 1507-1516

62. Zeng, Z., Yang, H., Huang, Z. Z., Chen, C., Wang, J., and Lu, S. C. (2001) The role of c-Myb in the up-regulation of methionine adenosyltransferase 2A expression in activated Jurkat cells. Biochem. J. 353, 163-168

63. Michalopoulos, G. K., and DeFrances, M. C. (1997) Liver regeneration. Science 276, 60-66

64. Huang, Z. Z., Mao, Z., Cai, J., and Lu, S. C. (1999) Changes in methionine adenosyltransferase during liver regeneration in the rat. Am. J. Physiol. 275, G14-G21

65. Garcia-Trevijano, E. R., Latasa, M. U., Carretero, M. V., Berasain, C., Mato, J. M., and Avila, M. A. (2000) S-Adenosylmethionine regulates MAT1A and MAT2A gene expression in cultured rat hepatocytes: a new role for S-adenosylmethionine in 
the maintenance of the differentiated status of the liver. FASEB J. 14, 2511-2518

66. Cai, J., Mao, Z., Hwang, J., and Lu, S. C. (1998) Differential expression of methionine adenosyltransferase genes influences the rate of growth of human hepatocellular carcinoma cells. Cancer Res. 58, 1444-1450

67. Downard, J. (2001) The ins and outs of signalling. Nature (London) 411, 759-762

68. Sherr, C. J., and Roberts, J. M. (1999) CDK inhibitors: positive and negative regulators of G1-phase progression. Genes Dev. 13, 1501-1512

69. Kato, A., Ota, S., Bamba, H., Wong, R. M., Ohmura, E., Imai, Y., and Matsuzaki, F. (1998) Regulation of cyclin D-dependent kinase activity in rat liver regeneration. Biochem. Biophys. Res. Commun. 245, 70-74

70. Albrecht, J. H., and Hansen, L. K. (1999) Cyclin D1 promotes mitogen-independent cell-cycle progression in hepatocytes. Cell Growth Differ. 10, 397-404

71. Harari, D., and Yarden, Y. (2000) Molecular mechanisms underlying ErbB2/HER2 action in breast cancer. Oncogene 19, 6102-6114

72. Garcea, R., Daino, L., Pascale, R., Simile, M. M., Puddu, M., Frassetto, S., Cozzolino, P., Seddaiu, M. A., Gaspa, L., and Feo, F. (1989) Inhibition of promotion and persistent nodule growth by S-adenosyl-L-methionine in rat liver carcinogenesis: role of remodeling and apoptosis. Cancer Res. 49, 1850-1856

73. Pascale, R. M., Marras, V., Simile, M. M., Daino, L., Pinna, G., Bennati, S., Carta, M., Seddaiu, M. A., Massarelli, G., and Feo, F. (1992) Chemoprevention of rat liver carcinogenesis by S-adenosylmethionine: a long-term study. Cancer Res. 52, 4979-4986

74. Lu, S. C., Alvarez, L., Huang, Z-Z., Chen, L., Corrales, F. J., Avila, M. A., Kanel, G., and Mato, J. M. (2001) Methionine adenosyltransferase 1A knockout mice are predisposed to liver injury and exhibit increased expression of genes involved in proliferation. Proc. Natl. Acad. Sci. USA 98, 5560-5565

75. Yang, S. Q., Lin, H. Z., Hwang, J., Chacko, V. P., and Diehl, A. M. (2001) Hepatic hyperplasia in noncirrhotic fatty livers: Is obesity-related hepatic steatosis a premalignant condition? Cancer Res. 61, 5016-5023

76. Rai, R. M., Lee, F. Y. J., Rosen, A., Yang, S. Q., Lin, H. Z., Koteish, A., Liew, F. Y., Zaragoza, C., Lowenstein, C., and Diehl, A. M. (1998) Impaired liver regeneration in inducible nitric oxide synthase-deficient mice. Proc. Natl. Acad. Sci. USA 95, 13829-13834

77. Best, C. H., Hershey, J. M., and Huntsman, M. E. (1932) The effect of lecithin on fat deposition in the liver of the normal rat. J. Physiol. (London) 75, 56-66

78. Newberne, P. M. (1986) Lipotropic factors and oncogenesis. Adv. Exp. Med. Biol. 206, 223-251

79. Shivapurkar, N., and Poirier, L. A. (1983) Tissue levels of S-adenosylmethionine and S-adenosylhomocysteine in rats fed methyl-deficient, amino acid-defined diets for one to five weeks. Carcinogenesis 4, 1051-1057

80. Cook, R. J., Horne, D. W., and Wagner, C. (1989) Effect of dietary methyl group deficiency on one-carbon metabolism in rats. J. Nutr. 119, 612-617

81. Lieber, C. S. (1997) Cytochrome P-4502E1: its physiological and pathological role. Physiol. Rev. 77, 517-544

82. Lieber, C. S. (2000) Alcohol: its metabolism and interaction with nutrients. Annu. Rev. Nutr. 20, 395-430

83. Tsukamoto, H., and Lu, S. C. (2001) Current concepts in the pathogenesis of alcoholic liver injury. FASEB J. 15, 1335-1349

84. Diehl, A. M. (1999) Nonalcoholic steatohepatitis. Semin. Liver Dis. 19, 221-229

85. Dai, Y., Rashba-Step, J., and Cederbaum, A. I. (1993) Stable transfection of human cytochrome P4502E1 in HepG2 cells: Characterization of catalytic activities and production of reactive oxygen intermediates. Biochemistry 32, 6928-6937

86. Wu, D., and Cederbaum, A. I. (1996) Ethanol citotoxicity to a transfected HepG2 cell line expressing human cytochrome P4502E1. J. Biol. Chem. 271, 23914-23919

87. Morimoto, M., Hagbjork, A. L., Wan, I. J., Fu, P. C., Clot, P., Albano, E., Ingelman-Sundberg, M., and French, S. (1995) Modulation of experimental alcohol-induced liver disease by cytochrome P4502E1 inhibitors. Hepatology 21, 1610-1617

88. Kono, H., Bradford, B. U., Yin, M., Sulik, K. K., Koop, D. R., Peter, M. J., Gonzalez, F. J., McDonald, T., Dikalove, A., Kadiiska, M. B., Mason, R. P., and Thurman, R. G. (1999) CYP2E1 is not involved in early alcohol-induced liver injury. Am. J. Physiol. 277, 1259-1267

89. Leclercq, I. A., Farrell, G. C., Field, J., Bell, D. R., Gonzalez, F. J. and Robertson, G. R. (2000) CYP2E1 and CYP4A as microsomal catalysts of lipid peroxides in murine nonalcoholic steatohepatitits. J. Clin. Invest. 105, 1067-1075

90. Weltman, M. D., Farrell, G. C., Hall, P., Ingelman-Sundberg, M. and Liddle, C. (1998) Hepatic cytochrome P4502E1 is increased in patients with nonalcoholic steatohepatitis. Hepatology 27, 128-133

91. Enriquez, A., Leclercq, I., Farrell, G. C., and Robertson, G. R. (1999) Altered expression of hepatic CYP2E1 and CYP4A in obese, diabetic ob/ob mice and fa/fa Zucker rats. Biochem. Biophys. Res. Commun. 255, 300-306

92. Lu, S. C. (1999) Regulation of hepatic glutathione synthesis: current concepts and controversies. FASEB J. 13, 1169-1183

93. Mari, M., and Cederbaum, A. I. (2000) CYP2E1 overexpression in HepG2 cells induces glutathione synthesis by transcriptional activation of $\gamma$-glutamylcysteine synthetase. J. Biol. Chem. 275, $15563-15571$

94. Chou, J. Y. (2000) Molecular genetics of hepatic methionine adenosyltransferase deficiency. Pharmacol. Ther. 85, 1-9

95. Lieber, C. S. (1999) Role of S-adenosylmethionine in the treatment of liver diseases. J. Hepatol. 30, 1155-1159

96. Mato, J. M., Camara, J., Fernandez, P., Caballeria, L., Coll, S., Caballero, A., Garcia-Buey, L., Beltran, J., Benita, V., Caballeria, J., Sola, R., Moreno-Otero, R., Barrao, F., Martin-Duce, A., Correa, J. A., Pares, A., Boissard, G., Ortiz, P., and Rodes, J. (1999) S-Adenosylmethionine in alcoholic liver cirrhosis: a randomized, placebo-controlled, double-blind, multicenter clinical trial. J. Hepatol. 30, 1081-1089 